\title{
Investigation of resistance formation mechanisms for contacts to $n$-AIN and $n$-GaN with a high dislocation density
}

\author{
A.V. Sachenko ${ }^{1}$, A.E. Belyaev ${ }^{1}$, N.S. Boltovets' ${ }^{2}$, Yu.V. Zhilyaev ${ }^{3}$, L.M. Kapitanchuk ${ }^{4}$, V.P. Klad'ko' ${ }^{1}$, \\ R.V. Konakova ${ }^{1}$, Ya.Ya. Kudryk ${ }^{1}$, A.V. Kuchuk ${ }^{1}$, A.V. Naumov ${ }^{1}$, V.V. Panteleev ${ }^{3}$, V.N. Sheremet ${ }^{1}$ \\ ${ }^{I}$ V. Lashkaryov Institute of Semiconductor Physics, NAS of Ukraine, 03028 Kyiv, Ukraine \\ Phone: 38(044) 525-61-82; fax: 38(044) 525-83-42; e-mail: konakova@isp.kiev.ua \\ ${ }^{2}$ State Enterprise Research Institute “Orion”, 03057 Kyiv, Ukraine \\ ${ }^{3}$ Ioffe Physical-Technical Institute, Russian Academy of Sciences, 194021 Sankt-Peterburg, Russia \\ ${ }^{4}$ Paton Institute of Electric Welding, NAS of Ukraine, 03068 Kyiv, Ukraine
}

\begin{abstract}
We studied temperature dependences of the resistivity, $\rho_{c}(T)$, of Pd-Ti-Pd-Au ohmic contacts to wide-gap semiconductors $n-\mathrm{GaN}$ and $n-\mathrm{AlN}$ with a high dislocation density. Both $\rho_{c}(T)$ curves have portions of exponential decrease, as well as those with very slight $\rho_{c}(T)$ dependence at higher temperatures. Besides, the Au-Pd-Ti$\mathrm{Pd}-n$-GaN contacts have a portion of $\rho_{c}(T)$ flattening out in the low-temperature region. This portion appears only after rapid thermal annealing (RTA). In principle, its appearance may be caused by preliminary heavy doping of the near-contact region with a shallow donor impurity as well as doping in the course of contact formation owing to RTA, if the contact-forming layer involves a material atoms of which serve as shallow donors in III $-\mathrm{N}$ compounds. The obtained $\rho_{c}(T)$ dependences cannot be explained by the existing mechanisms of current transfer. We propose other mechanisms explaining the experimental $\rho_{c}(T)$ curves for ohmic contacts to $n-\mathrm{GaN}$ and $n-\mathrm{AlN}$.
\end{abstract}

Keywords: contact resistivity, III-N compounds, dislocation density.

Manuscript received 22.08.12; revised version received 25.09.12; accepted for publication 17.10.12; published online 12.12.12.

\section{Introduction}

In recent years, both the materials science of III-N compounds and manufacturing technology of various devices based on these compounds (light-emitting and Schottky barrier diodes, field-effect transistors, etc.) are actively elaborated. The corresponding elemental base is predominantly developed with $\mathrm{GaN}$ and its solid solutions [1-6]. InN and solid solutions in the InN-GaNAlN system are also promising materials for optoelectronic devices. And AIN serves as material for substrates in a number of device structures.

Formation of ohmic contacts to $\mathrm{GaN}$ and $\mathrm{InN}$ (as well as to AlN with its higher resistivity) still makes a complicated problem. According to classic models, making the ohmic contact requires that the electron work function of metal, $\varphi_{m}$, be less than the electron affinity $\chi$ of $n-\mathrm{AlN}$ [7]. Since AlN is a wide-gap material with low electron affinity $\left(\chi_{\mathrm{AIN}}=0.6 \mathrm{eV}\right)$ [8], its electron work function $\varphi_{m}$ exceeds $\chi_{\text {AlN }}$. Therefore, formation of ohmic contacts to AlN within the framework of classic models presents some difficulties.

Most of III-N compounds are wide-gap. That is why the present-day devices made on their basis demonstrate operation temperatures 1.5-2 times higher than those of silicon and gallium arsenide devices $[4,5]$. Therefore, ohmic contacts are obtained at rather high temperatures of contact-forming layers firing. This favors appearance of structurally-imperfect metal-semiconductor interface, in particular, with a high dislocation density in the nearcontact region of the III $-\mathrm{N}$ heterostructures grown predominantly on foreign substrates. The authors of [911] noted that metal shunts associated with dislocations 
can form in the near-contact regions of such structures. As a result, the contact resistivity $\rho_{c}$ increases with temperature. This is related to temperature dependence of metal resistivity and is very undesirable for devices operating at elevated temperatures.

In [12] it was reported on a mechanism of shunt formation owing to indium diffusion via dislocations from the contact formed with indium-tin alloy in gallium nitride light-emitting diodes. In our papers $[13,14]$, it was shown that temperature dependence of contact resistivity $\rho_{c}(T)$ in such ohmic contacts is more complicated than linear. In this case, growing as well as decreasing with temperature $\rho_{c}(T)$ curves are possible.

As to the ohmic contacts to high-resistance AlN, there is no detailed information on them in literature, except for the paper [15] where In-AlN alloyed contact was considered. It was noted that the above contact was high-resistance, with linear current-voltage characteristic, and its resistance was close to the bulk one. We did not manage to find literature data on $\rho_{c}(T)$ dependence of ohmic contacts to $n-\mathrm{AlN}$.

The objective of this work is investigation of the features of $\rho_{c}(T)$ curves of ohmic contacts to $n-\mathrm{GaN}$ and $n-\mathrm{AlN}$ grown on foreign substrates.

\section{Experimental procedure}

The single-crystalline GaN and AlN films were prepared at the Ioffe Physical-Technical Institute, using chloride vapor-phase epitaxy, at a standard setup with a horizontal reactor [16]. The GaN layers (thickness of $\sim 30 \mu \mathrm{m}$, donor concentration $>10^{18} \mathrm{~cm}^{-3}$ ) were grown on an AlN "template" on sapphire. The high-resistant AlN layers (thickness of $\sim 3.5 \mu \mathrm{m}$ ) were grown on a heavily doped $n^{+}-\mathrm{SiC}$ substrate.

X-ray diffraction measurements on the GaN (AIN) layers showed that half-width of X-ray diffraction peak was $\omega_{0} \sim 5 \operatorname{arcmin}(30 \operatorname{arcmin})$. The mean linear dislocation density was $\leq 10^{5} \mathrm{~cm}^{-1}$. Using consecutive vacuum deposition onto substrates heated to $350{ }^{\circ} \mathrm{C}$, the $\mathrm{Au}-\mathrm{Pd}-\mathrm{Ti}$ $\mathrm{Pd}-n-\mathrm{GaN}(\mathrm{AlN})$ contact metallization was prepared on both samples. Then test structures with linear and radial geometry of templates were formed to measure contact resistivity with the transmission line method (TLM) [17] in the 100 to $380 \mathrm{~K}$ temperature range.

Ohmic contacts on the Au-Pd-Ti-Pd- $n-G a N$ structures were made on the substrate heated to $350{ }^{\circ} \mathrm{C}$ as well as with further rapid thermal annealing (RTA) at $T=900{ }^{\circ} \mathrm{C}$ for $30 \mathrm{~s}$. Ohmic contact to the Au-Pd-Ti-Pd$n$-AlN structure was formed after such RTA only.

We used Auger electron spectroscopy (LAS 2000 spectrometer) in combination with ion etching $(1 \mathrm{keV}$ $\mathrm{Ar}^{+}$ions) to study component concentration depth profiles in the metallization layers. The cleavages of ohmic contacts and morphological features of $\mathrm{GaN}$ and
AlN film surfaces were studied using a Field Emission Auger Microprobe JAMP 9500F in the scanning electron microscopy mode.

Shown in Fig. 1a are component concentration depth profiles in the Au-Pd-Ti-Pd- $n$-GaN contact metallization. One can see that this contact system has a layered structure of metallization with a rather abrupt interface between contact-forming metal (palladium) and gallium nitride. This interface was formed in the course of $\mathrm{Pd}$ deposition onto the substrate ( $\mathrm{GaN}$ surface) heated to $350{ }^{\circ} \mathrm{C}$. Fig. $2 \mathrm{a}$ presenting a fragment of Au-Pd-Ti$\mathrm{Pd}-n-\mathrm{GaN}$ contact cleavage confirms presence of a rather abrupt metal-GaN interface. One can also see columnar structure of the $n-\mathrm{GaN}$ film at the cleavage.

However, the GaN film has a rather high density of hexagonal defects (see Figs $2 b$ to $2 f$ ), in particular, with the lateral dimension close to $10 \mu \mathrm{m}$ (Figs 2c and 2d) and funnel-shaped deepening with metallized surface after contact deposition (Fig. 2e), at the depth of 4 to $6 \mu \mathrm{m}$ from the surface at a fragment of TLM structure (i.e., a test structure intended for measurement of $\rho_{c}$ using TLM). A fragment of GaN surface with such defects is presented in Fig. 2f. Similar hexagonal defects were observed in [6] on thick GaN layers grown on GaAs substrates. The resistivity of Au-Pd-Ti-Pd- $n-G a N$ ohmic contacts measured at room temperature was $6.7 \cdot 10^{-5} \mathrm{Ohm} \cdot \mathrm{cm}^{2} \quad\left(7.8 \cdot 10^{-5} \mathrm{Ohm} \cdot \mathrm{cm}^{2}\right)$ for linear (radial) TLM topology.
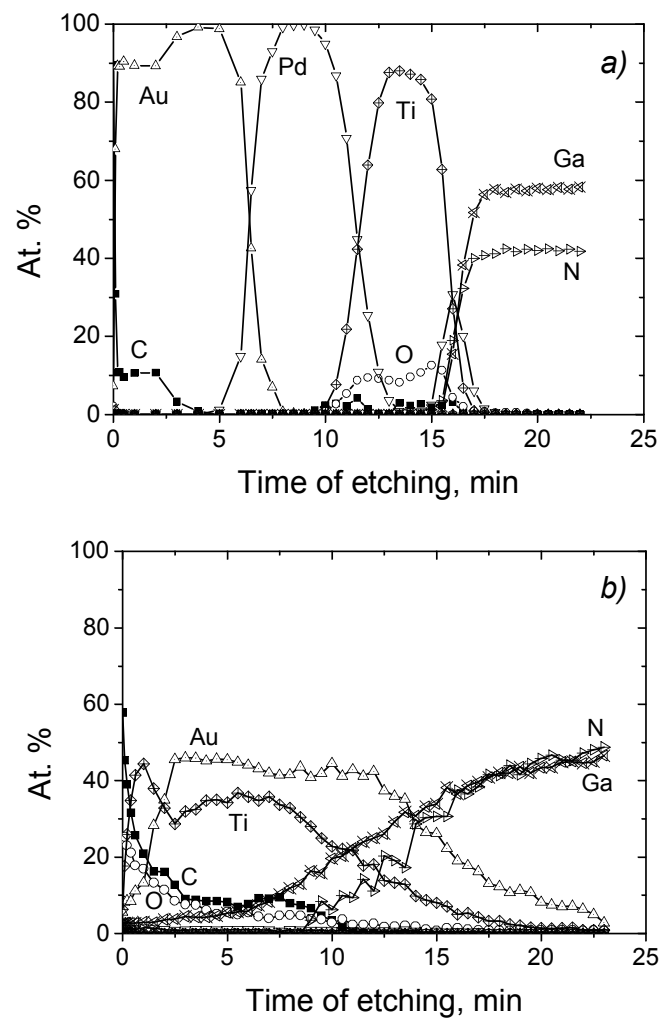

Fig. 1. Component concentration profiles in the Au-Pd-Ti-Pd$n$-GaN contact metallization: $a-$ initial, $b-$ after RTA at $900{ }^{\circ} \mathrm{C}$ for $30 \mathrm{~s}$. 


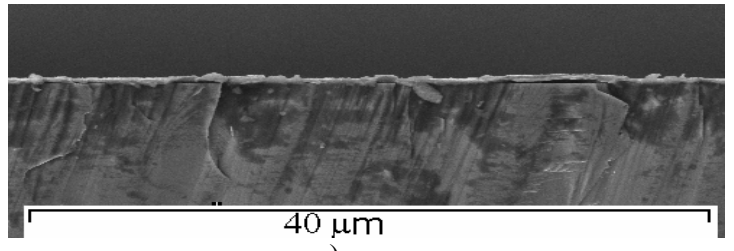

a)

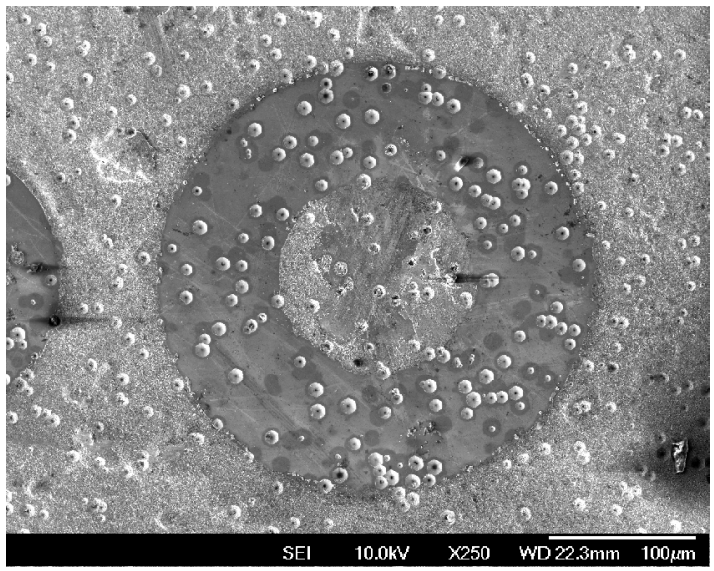

c)

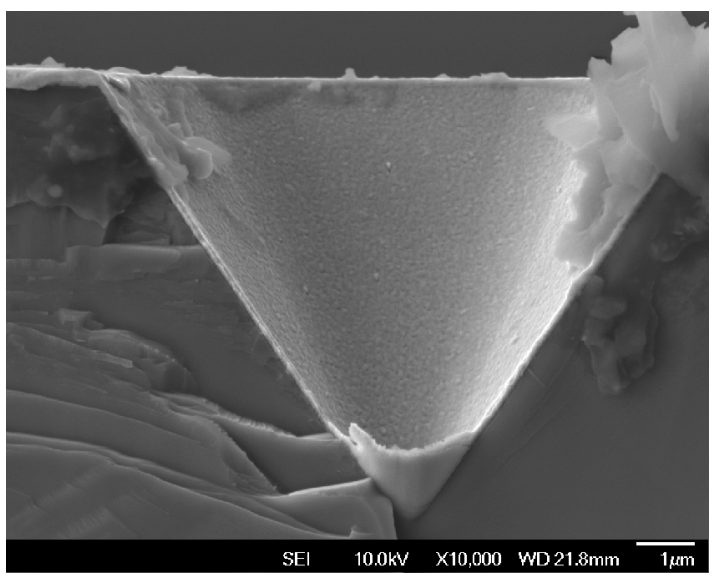

e)

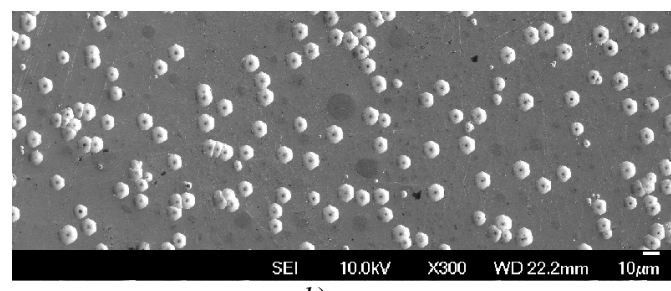

b)

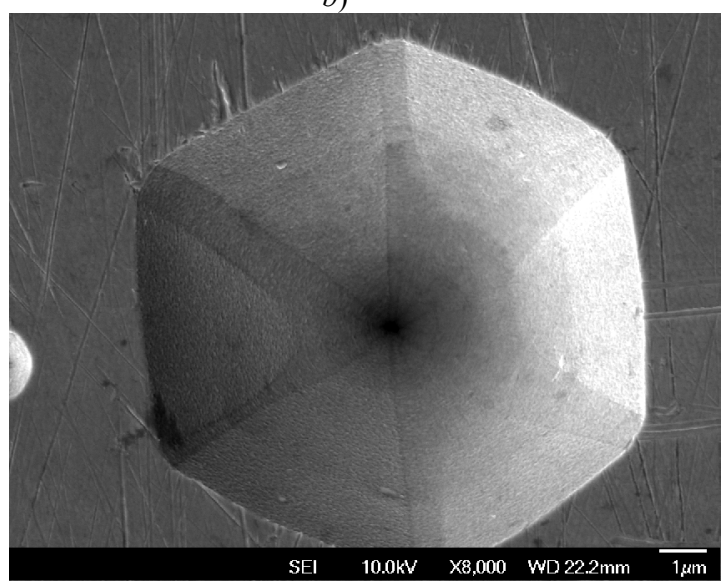

d)

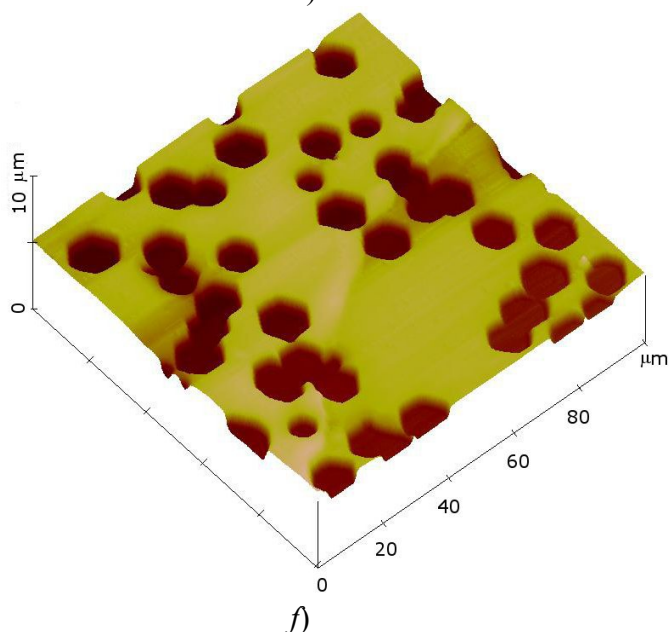

f)

Fig. 2. $a$ - pattern of an Au-Pd-Ti-Pd- $n$-GaN contact cleavage fragment; $b$ - morphology of GaN film surface with hexagonal defects; $c$ - fragment of a TLM structure with hexagonal defects; $d$ - morphology of a hexagonal defect; $e$ - a funnel-shaped metallization defect; $f-3 \mathrm{D}$ fragment of a sample with hexagonal defects.

Fig. 3a presents component concentration depth profiles in the Au-Pd-Ti-Pd- $n$-AlN contact metallization formed on a substrate heated to $350^{\circ} \mathrm{C}$. One can see that the metal-AlN interface is considerably smeared. This is a region of mixing the AlN components, $\mathrm{Pd}$ and $\mathrm{Ti}$ with a portion (up to 10 atomic percent) of oxygen in the Ti and Pd layers. A cleavage of the Au-Pd-Ti-Pd- $n$-AlN contact structure (Fig. 4) confirms structural nonuniformity of the metal-AIN interface. In this case, one can see from the morphology of the initial $n-$ AlN film (Fig. 5) that this film has pores $\sim 40 \mathrm{~nm}$ in diameter.

$X$-ray diffraction data (XRD) for contact structures Au-Pd-Ti-Pd- $n$-GaN(AIN) are shown in Fig. 6. In the
XRD spectra from the initial samples, the reflections of $\mathrm{Au}(111,200)$ and Pd (111) from polycrystalline metal layers are observed. The absence of reflections from the Ti film is apparently related to the so-called X-ray amorphous state of titanium, which has a metallic conductivity. (Structural quality (half-width and intensity of the peaks) of $\mathrm{Au}$ and Pd films is much better on GaN substrate than on the AlN substrate). After annealing, the following phase transitions are observed. For AIN substrate, annealing leads to the interdiffusion of metal atoms plating and the formation of $\mathrm{Au}_{\mathrm{x}}(\mathrm{Pd}, \mathrm{Ti})_{1-\mathrm{x}}$ solid solution. The observed peak at $\sim 38.2^{\circ}$ indicates that some fraction of pure $\mathrm{Au}$ is remained. 

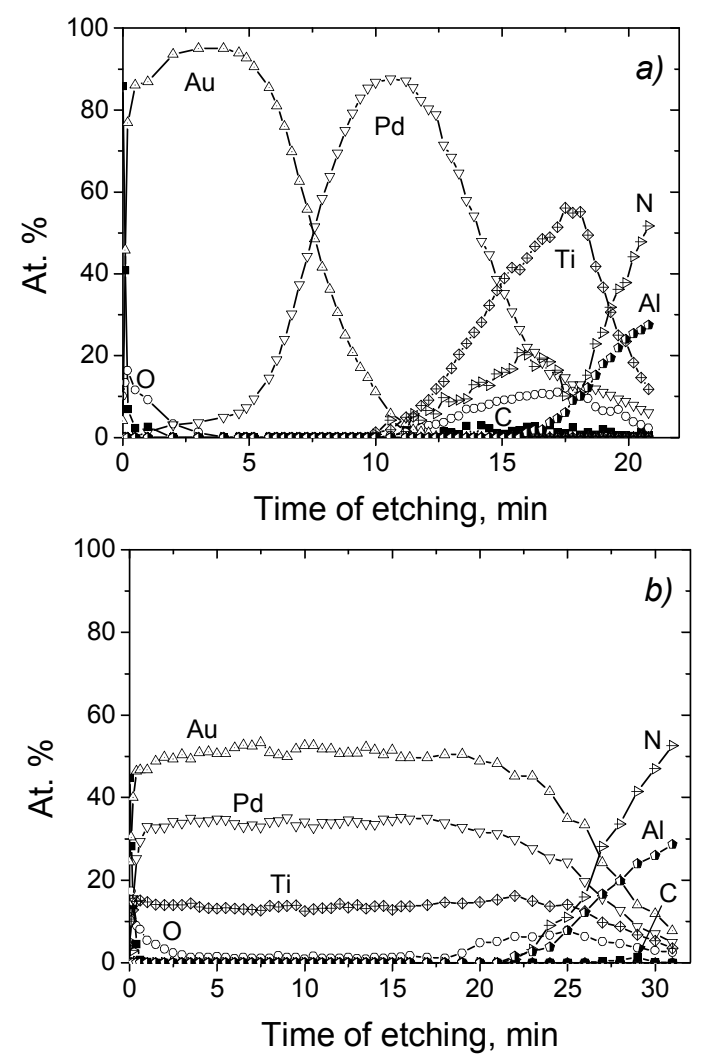

Fig. 3. Component concentration profiles in the Au-Pd-Ti-Pd$n$-AlN contact metallization: $a-$ initial; $b-$ after RTA at $900{ }^{\circ} \mathrm{C}$ for $30 \mathrm{~s}$.

For GaN substrate, annealing also leads to interdiffusion of metal atoms. However, in this case, the formation of $\mathrm{Pd}_{3} \mathrm{Ti}$ phases, as well as two nonstoichiometric phases (solid solutions) based on $\mathrm{Au}$ with lattice constant smaller and larger than in pure gold. We assume that closer to the interface the Ga-rich solid solution of $\mathrm{Au}_{\mathrm{x}} \mathrm{Ga}(\mathrm{Pd}, \mathrm{Ti})_{1-\mathrm{x}}$ is formed. And closer to the surface, the Pd-rich solid solution of $\mathrm{Au}_{\mathrm{x}} \mathrm{Pd}(\mathrm{Ga}, \mathrm{Ti})_{1-\mathrm{x}}$ is formed. So, in the case of $\mathrm{GaN}$ substrate, interaction between metallization and substrate is observed.

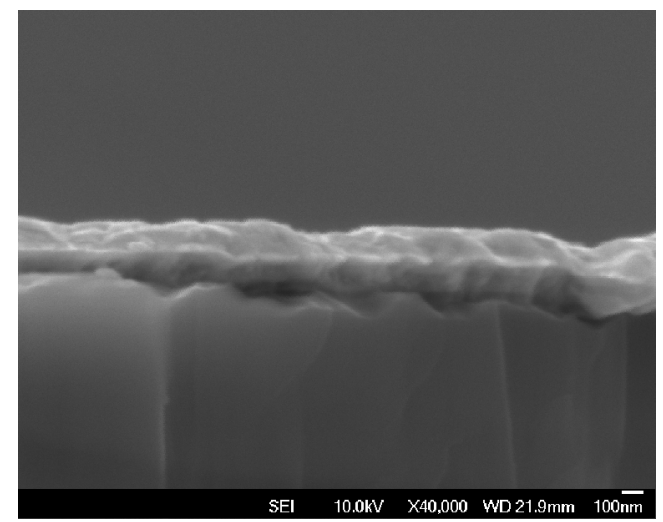

Fig. 4. Pattern of an Au-Pd-Ti-Pd- $n$-AlN contact cleavage fragment.

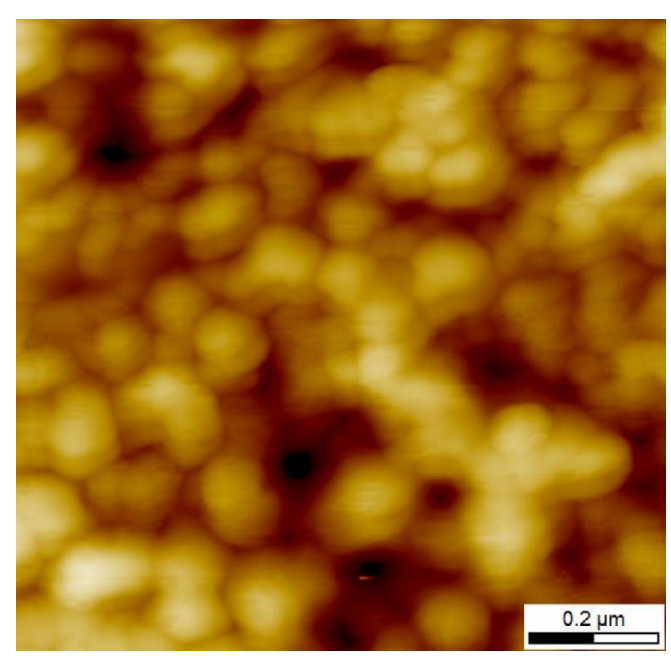

Fig. 5. Morphology of $n$-AIN film surface.

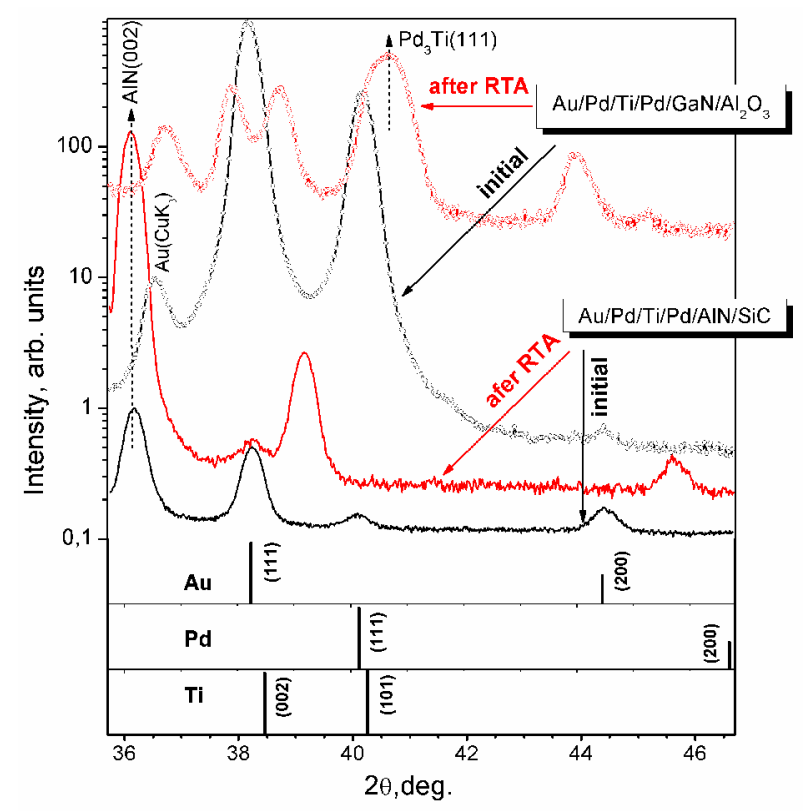

Fig. 6. Fragments of $\mathrm{X}$-ray diffraction patterns for $\mathrm{Au}-\mathrm{Pd}-\mathrm{Ti}$ $\mathrm{Pd} / \mathrm{AlN} / \mathrm{SiC}$ and $\mathrm{Au}-\mathrm{Pd}-\mathrm{Ti}-\mathrm{Pd} / \mathrm{GaN} / \mathrm{Al}_{2} \mathrm{O}_{3}$ structures.

The Au-Pd-Ti-Pd- $n$-AlN contact formed after metal deposition onto a substrate heated up to $350{ }^{\circ} \mathrm{C}$ is a highresistance non-ohmic contact. It becomes ohmic after RTA at $T=900{ }^{\circ} \mathrm{C}$ for $30 \mathrm{~s}$ only. Resistivity of such a contact measured at room temperature on a radial test TLM structure was $0.05 \mathrm{Ohm} \cdot \mathrm{cm}^{2}$. It should be noted that an alloyed $\mathrm{In}-n-\mathrm{GaN}$ ohmic contact with $n \approx 10^{18}$ and $8 \cdot 10^{18} \mathrm{~cm}^{-3}$ demonstrated $\rho_{c}$ of the same order at $T=300 \mathrm{~K}$ [15]. It was also found that, after RTA at $900{ }^{\circ} \mathrm{C}$ for $30 \mathrm{~s}$, metallization components of contact structures on AlN and GaN were intermixed (see Figs 1c and $3 \mathrm{c}$, respectively). 


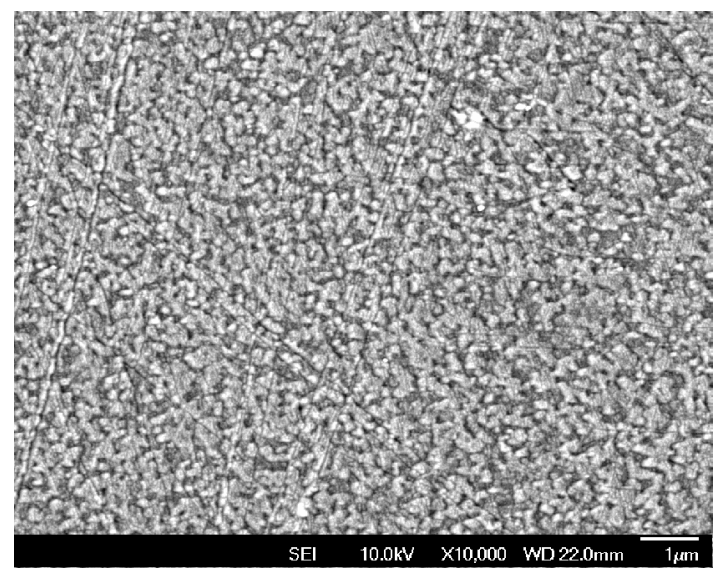

a)

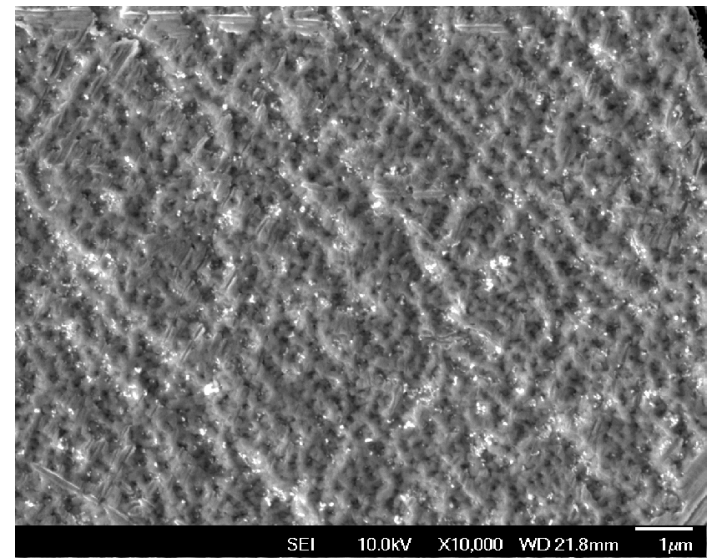

c)

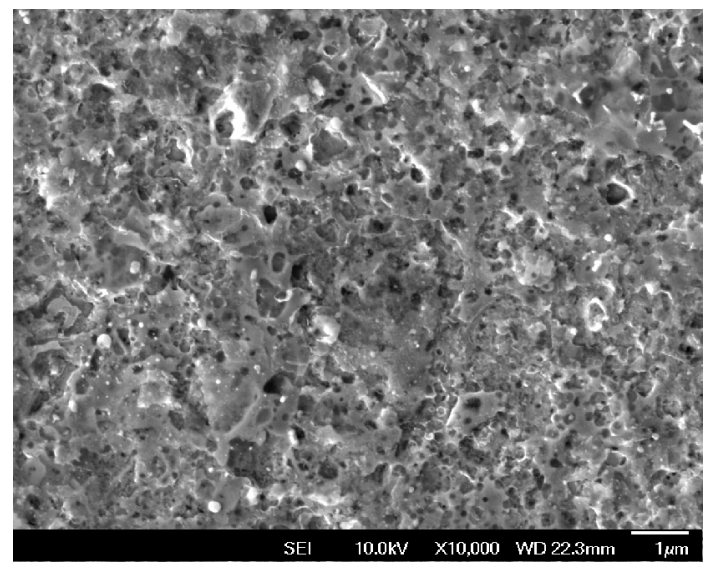

b)

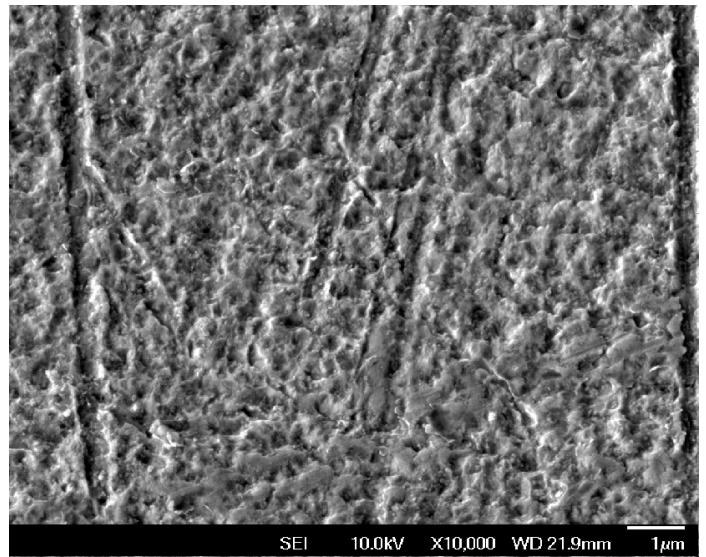

d)

Fig. 7. Morphology of Au film surface in Au-Pd-Ti-Pd- $n-\mathrm{GaN}$ contact metallization ( $a-$ initial; $b-$ after RTA at $900^{\circ} \mathrm{C}$ for $\left.30 \mathrm{~s}\right)$ and in Au-Pd-Ti-Pd- $n$-AlN contact metallization ( $c$-initial; $d$-after RTA at $900{ }^{\circ} \mathrm{C}$ for $\left.30 \mathrm{~s}\right)$.

Intense mass transport in contact metallization manifested itself also at the surface of the upper metal layer ( $\mathrm{Au}$ films) - see Figs $7 \mathrm{a}$ to $7 \mathrm{~d}$. One can see from comparison of initial samples with those subjected to RTA that after RTA gold coating on the contact metallization to GaN is more non-uniform than that on AlN. The morphology data on the Au films correlate with the contact concentration depth profiles in those contacts. However, the cleavage structure in the Au-PdTi-Pd- $n$-GaN $(n-\mathrm{AlN})$ contacts did not change qualitatively after RTA.

\section{Experimental results and discussion}

Shown in Fig. 8 are the temperature dependences of the contact resistivity, $\rho_{c}(T)$, for annealed ohmic contacts Au-Pd-Ti-Pd- $n$-AlN (curve I) and Au-Pd-Ti-Pd- $n$-GaN (curve II). A comparison of $\rho_{c}(T)$ curves for ohmic contacts to $n$ - AlN and $n-\mathrm{GaN}$ showed that in both cases, at low temperatures of measurement, $\rho_{c}$ decreases as temperature grows from 160 up to $200 \mathrm{~K}$ $(250 \mathrm{~K})$ for contacts to $n-\mathrm{GaN}(n-\mathrm{AlN})$. At further growth of temperature up to $375 \mathrm{~K}, \rho_{c}$ varies but slightly. The considerable distinction between the above dependences is that at room temperature the $\rho_{c}$ value for ohmic contact to $n$ - AIN is three orders higher than that to $n-\mathrm{GaN}$. The reason is related with the lower doping level of $n-\mathrm{AlN}$. Besides, as one can see from Fig. 8 (curve II), at low temperatures $(100$ to $150 \mathrm{~K}$ ) the $\rho_{c}$ value for ohmic contact to $n-\mathrm{GaN}$ practically does not depend on temperature. The current-voltage characteristics of all the contacts under investigation are linear in the 100 to $375 \mathrm{~K}$ temperature range.

To explain these effects, a novel concept of current transfer (adequate in the case of high dislocation density in semiconductor) was proposed in $[13,14]$. This concept takes into account current flow through metal shunts (associated with dislocations) and current limitation by diffusion supply of electrons. The currents flowing between dislocations were neglected. The 


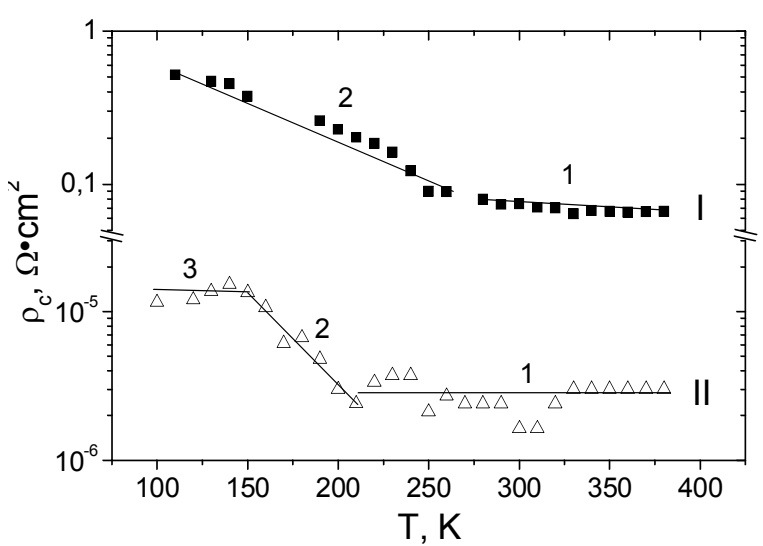

Fig. 8. Temperature dependence $\rho_{c}(T)$ after RTA at $900{ }^{\circ} \mathrm{C}$ for $30 \mathrm{~s}$ in ohmic contacts Au-Pd-Ti-Pd-n-AlN (curve I) and Au-Pd-Ti-Pd- $n$-GaN (curve II).

contact resistivity $\rho_{c}$ may increase or decrease with temperature, depending on the predominant mechanism of electron scattering. However, $\rho_{c}(T)$ presented in Fig. 8 cannot be explained by either the existing models for current transport in ohmic contacts [7] or the concept proposed in $[13,14]$.

Let us start discussion of the results obtained from the curve II (Fig. 8). It presents temperature dependence of the contact resistivity for ohmic contacts to $\mathrm{GaN}$ on the $\mathrm{Al}_{2} \mathrm{O}_{3}$ substrate. One can see that curve II has three portions: 1) very weak dependence $\rho_{c}(T)$ in the 200$380 \mathrm{~K}$ temperature range, 2) exponential dependence, with activation energy about $0.1 \mathrm{eV}$, in the $160-200 \mathrm{~K}$ temperature range, and 3) $\rho_{c}$ does not depend on temperature at $T<160 \mathrm{~K}$.

In principle, the portion 1 may correspond to the mechanism of electron current flow through the metal shunts associated with dislocations, with current limitation by diffusion supply of electrons to the contact $[13,14]$. Growth of $\rho_{c}(T)$ in the portion 2 as temperature decreases is purely exponential. This cannot be explained by power dependence for electron mobility decrease due to scattering on dislocations or lowtemperature "freezing-out" of electrons. In our case, silicon is a shallow donor with ionization energy below $20 \mathrm{meV}$, and this has to result in increasing $\rho_{c}(T)$ curve at temperatures below $50 \mathrm{~K}$ only. Therefore, to explain the portion 2 one should assume that this is related to the structural disorder effect on metal shunt conductivity at low temperatures, which changes the conduction type from metallic to semiconductor one with a corresponding activation energy. This seems plausible if one takes into account that metal shunt diameter is close to atomic sizes and, in principle, a single defect could lead to activation-type conduction at low temperatures [18].

The currents flowing through dislocations associated with metal shunts as well as currents flowing between dislocations correspond to parallel connection of resistances. Therefore, the plateau of the $\rho_{c}(T)$ curve in the portion 3 at $T<160 \mathrm{~K}$ is to be related to the current flowing between dislocations in the case of heavily doped near-contact region and, correspondingly, strong degeneracy. Then the contact resistance is determined by the thermionic emission mechanism and practically does not depend on temperature (see $[13,14])$. The portion 3 appears for the Au-Pd-Ti-Pd- $n$ GaN structures under investigation after RTA only.

In principle, appearance of portion 3 may be related to previous heavy doping of the near-contact region with a shallow donor impurity as well as doping in the course of contact formation due to RTA, if the contact-forming layer involves material serving as a shallow donor in the III - N compound. The relatively high $\rho_{c}$ value in the portion 3 (of the order of $10^{-5} \mathrm{Ohm} \cdot \mathrm{cm}^{2}$ ) may be explained by potential nonuniformity at the interface plane within the Shklovskii-Efros theory [19].

In the case of contact to AlN (curve I in Fig. 8), the $\rho_{c}(T)$ curve has only two portions, 1 and 2 (without portion 3), whose presence is explained just as in the case of contact to GaN. In principle, portion 3 (plateau) may appear in the case of contact to AIN at lower temperatures than in the case of contact to $\mathrm{GaN}$.

The obtained results make it possible to draw some conclusions concerning specific character of the physical mechanisms responsible for current flow in ohmic contacts to wide-gap semiconductors with a high density of structural defects.

\section{Conclusion}

Investigation of the temperature dependence for the contact resistivity, $\rho_{c}(T)$, was performed for Au-Pd-TiPd- $n$-GaN $(n-\mathrm{AlN})$ ohmic contacts. It was found that, in the $380-200 \mathrm{~K}$ range, $\rho_{c}(T)$ is determined by current flow through metal shunts associated with dislocations and is limited by diffusion supply of electrons. In the 250-100 K (200-160 K) temperature range for ohmic contacts to $n$-AlN $(n-\mathrm{GaN})$, contact resistivity $\rho_{c}$ grows exponentially as temperature decreases. This behavior cannot be described by either thermionic emission or field emission. For the ohmic contact to $n-\mathrm{GaN}$, in the $160-100 \mathrm{~K}$ temperature range, $\rho_{c}$ does not depend on temperature. This is due to thermionic mechanism of current transport (at strong degeneracy) owing to current transfer between dislocations.

It is supposed that the exponential dependence $\rho_{c}(T)$ at low temperatures can be explained by taking into account the effects of structural disorder on conductivity of metal shunts having atomic sizes. According to [19], these effects are responsible for changing the conduction type from metallic to semiconductor one. 


\section{Acknowledgements}

This work was supported by the State Target Scientific and Technical Program of Ukraine "Nanotechnologies and nanomaterials" for 2010-2014.

\section{References}

1. H. Morkoç, Handbook of Nitride Semiconductors and Devices, Vol. 2. WILEY-VCH Verlag GmbH \&Co, KGaA, Weinheim, 2008.

2. F.E. Shubert, Light-Emitting Diodes, $2^{\text {nd }}$ Ed. Cambridge University Press, 2006.

3. Yu.G. Shreter, Yu.T. Rebane, V.A. Zykov, V.G. Sidorov, Wide-Gap Semiconductors. Nauka, Sankt-Peterburg, 2001 (in Russian).

4. R. Quay, Gallium Nitride Electronics. SpringerVerlag, Berlin-Heidelberg, 2008.

5. A.G. Vasil'ev, Yu.V. Kolkovskii, Yu.A. Kontsevoi, Microwave Wide-Gap Semiconductor Transistors. Tekhnosfera, Moscow, 2011 (in Russian).

6. Technology of Gallium Nitride Crystal Growth, Eds. D. Ehrentraut, E. Meissner, M. Bockowski. Springer-Verlag, Berlin, 2010.

7. S.M. Sze, K.K. Ng, Physics of Semiconductor Devices, $3^{\text {rd }}$ Ed. John Wiley and Sons, 2007.

8. Properties of Advanced Semiconductor Materials, Eds. M. Levinshtein, S. Rumyantsev, M. Shur. John Wiley and Sons, 2001.
9. T.V. Blank, Yu.A. Gol'dberg // Semiconductors, 41(11), p. 1263 (2007).

10. T.V. Blank, Yu.A. Gol'dberg, E.A. Posse // Semiconductors, 40(10), p. 1173 (2006).

11. T.V. Blank, Yu.A. Gol'dberg, E.A. Posse // Semiconductors, 43(9), p. 1164 (2009).

12. Chin-Yuan Hsu, Wen-How Lan, Yew Chung Sermon Wu // Jap. J. Appl. Phys. 44(10), p. 7424 (2005).

13. A.V. Sachenko, A.E. Belyaev, A.V. Bobyl, N.S. Boltovets, V.N. Ivanov, L.M. Kapitanchuk, R.V. Konakova, Ya.Ya. Kudryk, V.V. Milenin, S.V. Novitskii, I.S. Tarasov, V.N. Sheremet, M.Ya. Yagovkina // Semiconductors, 46(3), p.334 (2012).

14. A.V. Sachenko, A.E. Belyaev, N.S. Boltovets, R.V. Konakova, Ya.Ya. Kudryk, S.V. Novitskii, V.N. Sheremet, J. Li, S.A. Vitusevich // J. Appl. Phys. 111(8), 083701 (2012).

15. V.N. Bessolov, T.V. Blank, Yu.A. Gold'berg, O.V. Konstantinov, E.A. Posse // Semiconductors, 42(11), p. 1315 (2008).

16. Yu.V. Zhilyaev, S.N. Rodin // Techn. Phys. Lett. 36(5), p. 397 (2010).

17. D.K. Schroder, Semiconductor Material and Device Characterization. Wiley, New Jersey, 2006.

18. Y. Imry, Introduction to Mesoscopic Physics. Oxford University Press, 2002.

19. B.I. Shklovskii, A.L. Efros, Electronic Properties of Doped Semiconductors. Springer, Berlin, 1984. 